\title{
Repetition priming and the haptic recognition of familiar and unfamiliar objects
}

\author{
Matt Craddock and Rebecca Lawson \\ University of Liverpool, Liverpool, England
}

\begin{abstract}
In four experiments, we examined the haptic recognition of 3-D objects. In Experiment 1, blindfolded participants named everyday objects presented haptically in two blocks. There was significant priming of naming, but no cost of an object changing orientation between blocks. However, typical orientations of objects were recognized more quickly than nonstandard orientations. In Experiment 2, participants accurately performed an unannounced test of memory for orientation. The lack of orientation-specific priming in Experiment 1, therefore, was not because participants could not remember the orientation at which they had first felt an object. In Experiment 3, we examined haptic naming of objects that were primed either haptically or visually. Haptic priming was greater than visual priming, although significant cross-modal priming was also observed. In Experiment 4 , we tested recognition memory for familiar and unfamiliar objects using an old-new recognition task. Objects were recognized best when they were presented in the same orientation in both blocks, suggesting that haptic object recognition is orientation sensitive. Photographs of the unfamiliar objects may be downloaded from www.psychonomic.org/archive.
\end{abstract}

Object recognition is a task that people accomplish effortlessly. To this end, people often employ both touch and vision; however, object recognition has largely been studied in the visual domain. Haptic object recognition was long considered a poor relative of visual object recognition, since people's ability to recognize 2-D raisedline depictions of common objects by touch alone is quite poor (Lederman, Klatzky, Chataway, \& Summers, 1990; Loomis, Klatzky, \& Lederman, 1991). However, recognition of real, familiar objects by touch is both fast and accurate (Klatzky, Lederman, \& Metzger, 1985), and there is excellent cross-modal priming for familiar objects (Bushnell \& Baxt, 1999; Reales \& Ballesteros, 1999). Transfer between vision and haptics is easily accomplished, indicating substantial representational similarities between the two modalities. If these similarities are in the perceptual domain, then both modalities may exhibit similar performance under similar conditions when the same stimulus attributes can be perceived through both modalities. Thus, manipulations that induce effects in visual object recognition may induce similar effects in the haptic modality. We tested this hypothesis in the present studies.

Visual object recognition can be affected by changes in the orientation from which an object is perceived (see Lawson, 1999, for a review). Research has indicated that haptic object recognition may also display orientation sensitivity (Forti \& Humphreys, 2005; Lawson, in press; Newell, Ernst, Tjan, \& Bülthoff, 2001). In the present article, we investigate the susceptibility of the haptic system to manipulations of orientation and consider how this might inform our understanding of the mechanisms of object recognition in both visual and haptic modalities. Although the terms view and viewpoint have been used previously in haptic studies (Forti \& Humphreys, 2005; Newell et al., 2001), their meanings are not clearly specified in a haptic context. However, what constitutes a "view" depends on the orientation of the object with respect to the observer for both haptics and vision, so here the term orientation will be used.

\section{Haptic Object Processing}

Lederman and Klatzky (1987) proposed two models of haptic processing. The image-mediation model holds that, beyond the initial cutaneous and kinesthetic inputs, haptics uses the same processes as the visual system. Inputs received by the haptic sensors are translated into a visual image and are thereafter processed as if they had originated from visual sensors. Thus, the haptic and visual systems are argued to share common processes from an early stage. In contrast, the direct-apprehension model holds that haptics constitutes a separate perceptual system from vision, with its own processing and physiological apparatus. On this account, vision and haptics only share later processes and representations. These two models are not mutually exclusive, and they may describe the performance of the haptic system under different conditions.

Lederman et al. (1990) argued that the haptic recognition of 2-D raised-line pictures was poor because it forced the haptic system to use image mediation, which necessitates the integration of spatially and temporally separated details and the translation of this input into a visual image.

M. Craddock, m.craddock@liv.ac.uk 
Given that the field-of-view of the fingers is relatively limited in comparison with that of the eyes, this is a difficult task. When the visual system was forced to operate under similar conditions as those of the haptic system by limiting field-of-view and degrading image resolution, it also performed poorly (Loomis et al., 1991). Furthermore, 2-D depictions lack cues to which haptic object exploration is particularly attuned, such as surface texture and hardness (Lederman \& Klatzky, 1987).

In contrast, Lederman et al. (1990) argued that the superiority of haptic recognition of familiar, real 3-D objects (Klatzky et al., 1985) to haptic recognition of 2-D depictions of those objects (see, e.g., Klatzky, Loomis, Lederman, Wake, \& Fujita, 1993) arises because it can use direct apprehension. Cues present with real, 3-D stimuli (e.g., weight, texture) are absent from 2-D depictions. Real objects also allow the use of the natural exploratory hand movements that the haptic system typically employs (Lederman \& Klatzky, 1987). Lederman and colleagues therefore suggested that experiments with real, 3-D stimuli provide a better test of the specific capabilities of the haptic system than experiments using 2-D depictions of objects.

Both the image-mediation and the direct-apprehension models posit shared processes and representations between haptics and vision. However, they make differing predictions regarding the influence of orientation. Under the image-mediation model, the haptic and visual systems share the same representations at all levels and thus should exhibit the same orientation dependencies. However, under the direct-apprehension model, the physiological apparatus for haptically accessing representations differs greatly from that of the visual system. Haptics and vision only share representations at a higher, more abstract level. If the orientation dependencies seen in visual object recognition are driven by lower level, modality-specific representations, then the orientation sensitivity of the haptic system may differ from that of the visual system.

\section{Shared Object Representations \\ Between Haptics and Vision}

There is imaging evidence for shared resources for vision and haptics. Amedi, Malach, Hendler, Peled, and Zohary (2001) showed that both haptic and visual object exploration activate the lateral occipital complex (LOC). The LOC is an area particularly implicated in visual object recognition (Grill-Spector, Kourtzi, \& Kanwisher, 2001), and especially in the processing of visual shape (Kourtzi, Erb, Grodd, \& Bülthoff, 2003; Zhang, Weisser, Stilla, Prather, \& Sathian, 2004). In contrast, the LOC is not activated by auditory stimuli diagnostic of object identity, such as the sound of a car engine (Amedi, Jacobson, Hendler, Malach, \& Zohary, 2002). This evidence suggests that the LOC derives shape in both visual and haptic modalities; thus, that sharing of resources may begin at an earlier stage than that suggested by the direct-apprehension model proposed by Lederman et al. (1990). If both the haptic and visual systems use the LOC for shape processing, then it seems likely that both would use the same representation of shape for object recognition. Furthermore, Zhang et al. (2004) found that activity in the LOC during haptic object exploration was not predicted by participants' reports of vividness of mental imagery; rather than translating haptic input into a visual image, as in the image-mediation model, the input may be transformed into a bimodal shape representation via the LOC. Vuilleumier, Henson, Driver, and Dolan (2002) found that the LOC exhibited orientationdependent activity in response to visual object presentation. If the orientation effects observed behaviorally for visual object recognition are due to processing within the LOC, then similar orientation effects would be expected for haptic object recognition.

Other modality-specific pathways may also be involved in haptic object processing. For example, Reed, Shoham, and Halgren (2004) identified a potentially distinct pathway for haptic object recognition via the somatosensory association cortex. Object processing using such modalityspecific areas could result in different orientation-sensitive performance for visual versus haptic presentation, even if shape processing in LOC is not modality specific.

There is compelling behavioral evidence for efficient sharing of information about objects between vision and haptics. Reales and Ballesteros (1999) found that crossmodal priming between vision and haptics is excellent for familiar objects. In the first of their experiments, participants studied objects either visually or haptically. The level of processing was varied at study by having participants either generate a sentence including each object's name (deep encoding) or rate each object's volume (shallow encoding). At test, participants named each object when it was presented either to the same modality as that at study or to the other modality. There was no speed or accuracy cost associated with encoding condition or with a change in modality between study and test, indicating complete cross-modal transfer of priming.

Effects of the level of processing are commonly used to distinguish explicit from implicit memory. Typically, manipulations of levels of processing affect explicit but not implicit measures of memory (see, e.g., Meier \& Perrig, 2000). Reales and Ballesteros (1999) argued that the absence of a level of processing effect in their study indicated that both visual and haptic priming of naming were implicit, underpinned by abstract, presemantic, structural descriptions of object shape that were not modality specific.

Easton, Greene, and Srinivas (1997) also compared implicit and explicit measures of recognition of 3-D familiar objects. Their participants named visually or haptically presented objects at study. At test, they either named the objects again - an implicit priming task - or were asked to state which object they had been given before - an oldnew explicit recognition memory task. Both tasks were conducted either visually or haptically. Explicit memory showed modality specificity: Haptically studied objects were best recognized haptically, and visually studied objects were best recognized visually. Neither the haptic nor the visual implicit priming tasks showed a significant effect of study modality, but comparisons across the two suggested a marginal within-modal advantage. Both the explicit and implicit task results suggest that cross-modal transfer between vision and haptics may not be complete, contrary to Reales and Ballesteros's (1999) findings. 
Implicit measures are often less reliable than explicit measures (Buchner \& Brandt, 2003; Buchner \& Wippich, 2000; Meier \& Perrig, 2000). The reliability of a measure influences statistical power: Less reliable measures have less power to find an effect. Thus, the lack of both modality-specific priming and a level-of-processing effect reported by Reales and Ballesteros (1999) may have been due to low statistical power rather than to the operation of distinct memory systems.

Other evidence suggests that cross-modal priming may depend upon a network of representations spanning verbal, visual, and haptic codes of representation. Lacey and Campbell (2006) found that cross-modal recognition of familiar objects was unaffected by visual, verbal, or haptic interference either at study or at test. Since no one method of interference selectively influenced performance to a greater degree than any other, they suggested that object representations can be both formed and retrieved using a multitude of codes. However, in their studies, performance on familiar objects was close to ceiling, making it difficult to assess the relative contributions of each of these codes.

\section{Orientation Effects in Visual Object Recognition}

Familiar objects are recognized best in a canonical, preferred orientation (Palmer, Rosch, \& Chase, 1981). This may reflect early stages of visual processing and be a function of the ease with which a particular image can be encoded, rather than being attributable to an object-specific, long-term representation (Lawson \& Humphreys, 1998). The orientation sensitivity of object-specific priming of visual object recognition based on stored representations has been a matter of extensive debate (see Lawson, 1999, for a review).

In Biederman's (1987) recognition-by-components model of visual object recognition, objects are assumed to be segmented into their constituent parts and are represented by a description of those parts and their relations to each other. According to this model, recognition should be orientation independent: As long as an object's parts and their relations are observable, recognition is independent of the specific viewpoint of the observer and of the orientations from which that observer has previously seen the object. Biederman and Gerhardstein (1993) found evidence of orientation invariance in the priming of the naming of pictures of familiar objects across depth rotations and in the classification of novel, unfamiliar objects. In both cases, they argued that this was due to the availability of the same structural description of an object for both study and test orientations.

Biederman and Gerhardstein (1993) suggested that entry-level, everyday object recognition would usually be orientation invariant. They argued that orientation dependence would only occur in a limited set of circumstances, such as when recognition took place at the subordinate level. However, contrary to their predictions, numerous studies have demonstrated orientation-specific priming at the entry level of recognition. The identification of an object is primed more when repeated presentations are in the same orientation than in a different orientation (see, e.g., Lawson, 1999; Lawson \& Humphreys, 1996, 1998,
1999; Thoma \& Davidoff, 2006; Vuilleumier et al., 2002). The orientation invariance reported by Biederman and Gerhardstein (1993) may be due to the low reliability of implicit measures, such as name-priming tasks. Several attempts have been made to understand what determines whether object identification is orientation sensitive (see, e.g., Hayward, 2003; Stankiewicz, Hummel, \& Cooper, 1998; Tarr \& Cheng, 2003); the theoretical interpretation of orientation sensitivity of visual object recognition will not be discussed further here.

\section{Orientation Effects in Haptic Object Recognition}

If the haptic system is sensitive to orientation when engaged in the recognition of real 3-D objects, then this would be consistent with the hypothesis that representations are shared between haptics and vision and that, in both modalities, object recognition is mediated by orientation-dependent mechanisms. If haptic recognition is orientation invariant, then it might be so because the haptic system is not attuned to orientation, or because it compensates for the effect of orientation better than vision. It would also suggest that the representations shared between vision and haptics are orientation independent.

Most experiments conducted on haptic object recognition have not explicitly controlled or manipulated orientation and, instead, have permitted bimanual, free exploration (see, e.g., Ballesteros, Reales, \& Manga, 1999; Klatzky et al., 1985; Reales \& Ballesteros, 1999). As Newell et al. (2001) observed, an intuitive suggestion might be that the haptic representation of objects would be omnidirectional, since the thumbs and fingers of each hand can contact different sides of an object simultaneously, whereas the eyes can only see one side of an object at once. However, four recent studies have all indicated that haptic object recognition is sensitive to orientation (Forti \& Humphreys, 2005; Lacey, Peters, \& Sathian, 2007; Lawson, in press; Newell et al., 2001).

Newell et al. (2001) compared visual and haptic recognition of unfamiliar stimuli constructed from stacked plastic bricks. Recognition both within and across modalities exhibited orientation specificity. Within-modal recognition was best when no change of orientation occurred from study to test. In contrast, cross-modal recognition was best when objects were rotated back-to-front between study and test. Newell et al. argued that this pattern of results was due to the haptic system's preferring the back of objects, whereas the visual system prefers the front. However, this finding was for unfamiliar objects for which the back and front were specified only within the confines of the experiment. It may not extend to objects that have a true back and front. Furthermore, Newell et al.'s stimuli were all constructed from the same parts; only their spatial configuration changed. The objects had the same material, temperature, and compliance; thus, they did not encompass the wide variety of shapes and materials encountered in everyday recognition of familiar objects. If these cues are important for haptic object recognition, as Lederman et al. (1990) argued, then Newell et al.'s findings may lack ecological validity.

Lacey et al. (2007) found that performance on haptic and visual identification tasks, in which participants 
learned to associate wooden blocks (similar to the plastic blocks of Newell et al., 2001) with a number and then identified objects by number at subsequent presentations, was orientation sensitive within modality but not across modalities. The authors suggested that cross-modal identification was driven by orientation-independent representations, whereas within-modal identification was driven by orientation-dependent but modality-specific representations. Thus, haptic and visual orientation sensitivity may be produced by different mechanisms and may manifest differently in the two modalities. However, similar criticisms of ecological validity apply to the stimuli used by Lacey et al. as to the stimuli used by Newell et al.

Forti and Humphreys (2005) presented neuropsychological evidence from a study of cross-modal visuohaptic matching. Their patient, J.P., exhibited specific deficits in the retrieval of semantic information about objects, but was relatively good at accessing perceptual information. J.P. studied familiar, real objects haptically. The objects were obscured from view and attached to a support so that they could only be explored in one orientation. With both real objects and clay models of the objects, J.P. was better at matching visual presentations of a haptically studied object when it was in the same orientation at both study and test. Thus, cross-modal matching was best when there was no orientation change, contrary to Newell et al.'s (2001) finding that cross-modal recognition improved with a $180^{\circ}$ orientation change, and also contrary to Lacey et al.'s (2007) report of orientation-invariant cross-modal identification. One reason for this discrepancy may be because familiar objects typically have front and back orientations outside of any experimental context, whereas the unfamiliar stimuli used by Newell et al. and Lacey et al. did not.

Finally, Lawson (in press) used a sequential-matching task to examine how the difficulty of detecting shape changes might interact with orientation changes in the haptic modality. Participants were presented with plastic, 3-D models of familiar objects and morphs of midpoint shapes between two similar endpoint familiar objects, such as a midpoint shape between a bed and a chair. On match trials, the same object was presented twice either in the same orientation both times, or rotated in depth by $90^{\circ}$ from the first to the second presentation. On mismatch trials, two different-shaped objects were presented at either the same or different orientations. The similarity of the mismatch objects was varied to manipulate the difficulty of shape discrimination in the task. Participants were asked to detect whether a shape change had occurred. Orientation changes and discrimination difficulty affected both visual and haptic performance. In vision, the two factors interacted: The negative effects of orientation changes were greatest when shape discrimination was hardest. However, in haptics, these two factors had additive effects. This difference in the observed pattern of orientation sensitivity across matched studies, which varied only the modality of presentation, suggests that orientation dependency may have different causes for visual and haptic object recognition.

These findings leave two main questions unanswered with respect to the effect of orientation on haptic object recognition. First, does orientation dependence extend to the recognition of real, familiar objects? Newell et al.'s (2001) and Lacey et al.'s (2007) experiments demonstrating orientation dependence with unfamiliar objects differed quite markedly from both everyday object recognition and previous experiments testing visual object recognition. Lawson's (in press) experiment used 3-D plastic models of familiar objects, which-like the stimuli used by Newell et al.- lacked many of the cues to identity present in everyday objects, such as size and texture. These cues are likely to be orientation invariant and thus may permit the orientation-invariant recognition of real objects. Second, do familiar objects have preferred, canonical orientations when being recognized haptically, as is found visually (Palmer et al., 1981)? Forti and Humphreys (2005) specified that objects were felt in canonical and noncanonical orientations, but they did not test whether the canonical orientation was better recognized haptically. In addition, Forti and Humphreys's data came from a single neuropsychological case study, so it is important to test a large group of non-brain-damaged participants to establish the generality of their results.

\section{EXPERIMENT 1}

The effect of orientation changes on priming of the naming of familiar objects has not been systematically investigated in the haptic modality. Only Lawson (in press) and Forti and Humphreys (2005) have tested recognition of familiar objects following orientation changes. Lawson (in press) found orientation-sensitive performance, but she only tested plastic scale models of real objects. Forti and Humphreys' participant, J.P., displayed orientationdependent performance, but this was only demonstrated in a cross-modal haptic to visual matching task. Neither a unimodal, haptic-haptic matching condition nor a neurologically normal control group were tested. Furthermore, both Lawson (in press) and Forti and Humphreys used sequential matching tasks that only required object representations to be maintained for a few seconds. In contrast, Experiment 1 examined longer term priming using a naming task. Previous experiments demonstrating significant within- and cross-modal priming of naming of familiar objects did not manipulate orientation (see, e.g., Reales \& Ballesteros, 1999).

In Experiment 1, blindfolded, sighted participants identified familiar objects using bimanual, haptic exploration. Each object was presented in one of two ("easy," canonical, or "hard") orientations in the first block. In the second block, each object was presented again either at the same orientation as that in the initial, priming block, or at a different orientation. Additionally, a set of familiar objects that had not been presented in the first block was presented in the second block. The naming of these new items was compared with the naming of Block 1 objects and primed objects in Block 2 to check whether participants showed any general improvement at naming objects from the first to the second block. If the representations used to recognize the primed objects were orientation specific, then objects for which no orientation change occurred from study to test should have exhibited enhanced priming 
as compared with objects for which an orientation change occurred. However, if the mechanisms used to recognize the objects were orientation invariant, then there should be no cost associated with a change in orientation from study to test.

\section{Method}

Participants. Twenty-eight participants were drawn from the student population of the University of Liverpool either voluntarily or in return for course credit. Of those, 26 were female, and 5 were left-handed. A further 2 right-handed participants were recruited opportunistically. Ages ranged from 18 to 66 ( $M=23$ years). No participant in the presently reported studies took part in more than one experiment.

Stimuli. Forty-five familiar objects were presented; see the Appendix. A further five familiar objects were used as practice items Each object was glued to a $20-\mathrm{cm}^{2}$ ceramic tile (see Figure 1). Each object was assigned an easy, canonical orientation, chosen to represent a position in which the object would typically be experienced when using it with the right hand and when encountering it visually. Easy orientations were then rotated by either $90^{\circ}$ (32 items) or $180^{\circ}$ (13 items; see the Appendix) to yield a hard orientation.

Design and Procedure. The experimental objects were concealed behind a screen whenever participants were not blindfolded Participants remained seated throughout the experiment. First, they named 20 line drawings of objects shown on a Macintosh computer monitor to familiarize them with the requirements of a vocal naming task. No objects that would appear in the haptic trials were shown.
They were instructed to name the objects loudly and clearly, avoiding any unnecessary vocalizations.

Participants were then told that they would be required to name a series of objects by touch alone. They were shown the $50-\mathrm{cm}^{2}$ carpet tile on which the objects would be placed and the starting positions in which they should place their hands. These were indicated by pieces of masking tape at the center of the left and right edges of the carpet tile (see Figure 1). The tape allowed participants to locate the starting hand positions consistently without vision. Carpet tile was used to muffle sounds made by the placing of the objects and to minimize the rotation of the objects after the experimenter had placed them. Participants then put on a pair of safety goggles covered in masking tape and confirmed that they were unable to see the area in which the objects would be placed.

Participants completed a block of five trials with the practice objects, then a block of 36 priming trials, then a second block of 45 target trials. Participants were given a brief break between the two experimental blocks and were not informed that objects would be repeated. During the break, the objects were hidden, and participants were allowed to remove the goggles. Objects were split into five sets of nine and were allocated so that those that were expected to be particularly difficult to name were spread evenly throughout the sets, and so that each set contained objects with a similar variety of shapes and materials; see the Appendix.

Participants were allocated to five groups of 6 . Each group was required to name four of the five sets of objects in the first block and all five sets in the second block. Two of the four sets presented in the first block were at easy orientations, and two were at hard orientations. One of each of these pairs of sets was presented in the same orienta-
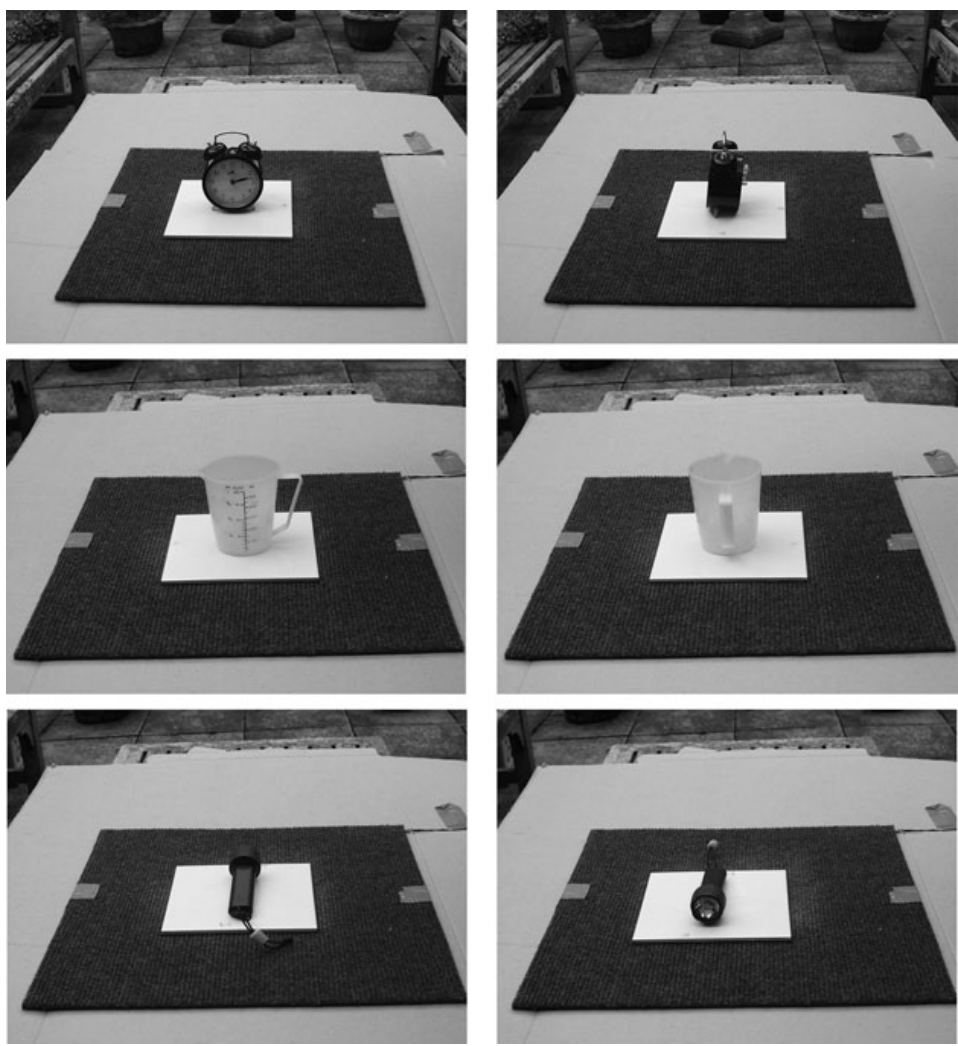

Figure 1. Photographs of the alarm clock, measuring jug, and torch used in Experiments 1-4. The left and right photographs show the easy and hard orientations, respectively, from the perspective of the participant. 
tion in the second block, and the other was presented in the different orientation. The fifth set of objects was presented only in the second block. The object sets assigned to each group were rotated using a Latin square design so that no two groups received the objects in the same combination (e.g., Group 1 was the only group given Set A in easy orientations in both experimental blocks). Each set of objects appeared in each of the five conditions an equal number of times.

The experimental software package PsyScope 1.2.5 (Cohen, MacWhinney, Flatt, \& Provost, 1993) generated a random order of presentation of objects within each block and was used to record responses. The experimenter placed an object in the center of the carpet tile in the appropriate orientation and then started each tria once the participants had positioned their hands on the tape markers. A single low-pitched warning beep was played, followed by a high-pitched double beep $1 \mathrm{sec}$ later to indicate that participants could start to touch the object. They were instructed not to reposition or lift the objects. Participants were given unlimited time to name each object aloud, but were instructed to do so both quickly and accurately. Each trial ended when either the participants named the object or declared that they did not know its name. Response times were recorded using a microphone headset attached to a Macintosh computer as a voice key. The experimenter recorded incorrect responses, voice key errors, and trials on which the participants moved at the wrong time (movement errors).

\section{Results}

Participants identified objects correctly on $95 \%$ of all trials, including trials that were later excluded from the analysis due to voice-key errors. Two participants were replaced because voice-key errors occurred on over $20 \%$ of trials, and 1 was replaced because the median reaction time (RT) was over $8 \mathrm{sec}$. Trials were excluded from RT analyses if a voice-key error occurred ( $6 \%$ of trials), a movement error was made $(1 \%)$, or an incorrect response was given (5\%). Correct trials that presented an object for which an error occurred in the other block were also excluded (7\%). Thus, for example, if an object was misnamed in Block 2 but was correctly named in Block 1, then RTs from both trials were excluded. Overall, $81 \%$ of the data was included in the RT analyses.

Mixed ANOVAs were conducted on the median correctnaming RTs and on the percentage of naming errors. ${ }^{1} \mathrm{Ex}-$ perimental block (1 or 2), Block 1 orientation (easy or hard), and Block 2 orientation (easy or hard) were used as within-participants factors. Group was used as a betweenparticipants factor in the by-participants analyses. Object set was used as a between-items factor in the by-items analyses. Effects involving these two counterbalancing factors are not reported. Post hoc Tukey's HSD tests were conducted on significant interactions. $F$ values in the byparticipants and by-items analyses are reported using subscripts: $F_{\mathrm{p}}$ and $F_{\mathrm{i}}$, respectively. New items, which were presented in Block 2 only, were analyzed separately.

Priming From Block 1 to Block 2. There were significant main effects of block for both RTs $\left[F_{\mathrm{p}}(1,25)=\right.$ 64.477, $\left.p<.001 ; F_{\mathrm{i}}(1,40)=85.779, p<.001\right]$ and errors $\left[F_{\mathrm{p}}(1,25)=19.082, p<.001 ; F_{\mathrm{i}}(1,40)=25.452\right.$, $p<.001]$. Responses in Block 2 (3,130 msec, $4 \%$ errors) were faster and more accurate than responses in Block 1 $(4,263 \mathrm{msec}, 7 \%)$. There was substantial priming of naming in Block 2. New items, which were presented in an easy orientation and in Block 2 only, were recognized neither faster $(4,102 \mathrm{msec})$ nor more accurately $(7 \%$ er- rors) than items presented in easy orientations in Block 1 $[4,040 \mathrm{msec}, t(29)=0.309 ; 6 \%$ errors, $t(29)=0.384$, $p=.7]$. Furthermore, these new items were named significantly slower than primed items presented in easy orientations in Block 2 [2,984 msec; $t(29)=8.167, p<$ $.001]$ and they tended to be named less accurately than primed items in Block 2 [4\% errors; $t(29)=1.648, p=$ .11]. Thus, there was no evidence that the increased speed and accuracy of naming of primed objects in Block 2 was due to a general improvement of participants at the task from the first to the second block. Instead, the substantial priming observed was object specific.

Effects of easy-hard orientation. Separated by block orientations, these results were as follows.

Block 1 orientation. In the by-participants analysis, there was a significant block $\times$ Block 1 orientation interaction for both RTs $\left[F_{\mathrm{p}}(1,25)=8.4, p=.008\right]$ and errors $\left[F_{\mathrm{p}}(1,25)=6.126, p=.02\right]$; see Figure 2 . In the by-items analysis, this interaction was not significant for RTs $\left[F_{\mathrm{i}}(1,40)=0.635, p=.43\right]$, but it was marginally significant for errors $\left[F_{\mathrm{i}}(1,40)=4.104, p=.049\right]$. Post hoc Tukey's HSD tests revealed that in Block 1, objects presented at easy orientations were recognized significantly faster and more accurately $(4,041 \mathrm{msec}, 6 \%)$ than objects presented at hard orientations $(4,485 \mathrm{msec}, 8 \%)$. However, in Block 2, there was no significant difference between objects that had previously been presented in easy $(3,094 \mathrm{msec}, 4 \%)$ rather than in hard $(3,165 \mathrm{msec}, 3 \%)$ orientations. Thus, Block 1 orientation influenced Block 1 naming, but not Block 2 naming.

Block 2 orientation. There was a significant block $\times$ Block 2 orientation interaction for RTs $\left[F_{\mathrm{p}}(1,25)=5.091\right.$, $\left.p=.03 ; F_{\mathrm{i}}(1,40)=5.037, p=.03\right]$, but not for errors $\left[F_{\mathrm{p}}(1,25)=1.086, p=.3 ; F_{\mathrm{i}}(1,40)=1.093, p=.3\right]$.

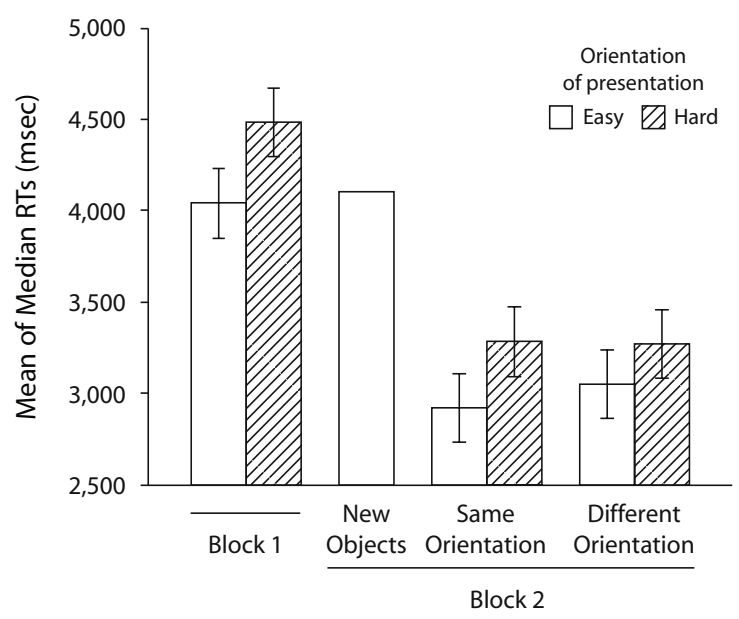

Figure 2. Mean of median response times (RTs, by participants) when naming objects presented at easy or hard orientations in Blocks 1 and $2(N=30)$. Error bars represent $95 \%$ withinparticipants confidence intervals calculated using the error term of the block $\times$ Block 1 orientation $\times$ Block 2 orientation interaction (Loftus \& Masson, 1994). Error bars are omitted for new objects, since they were not included in the main ANOVA. 
Post hoc Tukey's HSD tests did not find any significant difference between objects that would be presented at easy rather than at hard orientations in Block 2 for Block 1 responses (4,264 and 4,261 msec, respectively) or Block 2 responses (2,984 and 3,275 $\mathrm{msec})$. However, consistent with the results from Block 1, there was a trend for easy orientations in Block 2 to be named around $300 \mathrm{msec}$ faster than hard orientations. Thus, Block 2 orientation tended to influence Block 2 naming, but not Block 1 naming.

Effects of orientation changes from Block 1 to Block 2. Most importantly, the block $\times$ Block 1 orientation $\times$ Block 2 orientation interaction was not significant for RTs $\left[F_{\mathrm{p}}(1,25)=0.078, p=.78\right.$; see Figure 2; $\left.F_{\mathrm{i}}(1,40)=.55, p=.46\right]$ or for errors $\left[F_{\mathrm{p}}(1,25)=1.818\right.$, $\left.p=.19 ; F_{\mathrm{i}}(1,40)=3.959, p=.054\right]$. The marginally significant effect for errors in the items analysis is consistent with orientation-specific priming. However, overall, participants recognized primed objects as quickly - and as accurately - if there had been an orientation change from Block 1 to Block $2(3,158 \mathrm{msec}, 3 \%$ errors $)$ as if there had not $(3,101 \mathrm{msec}, 4 \%)$.

Axis of elongation. An additional factor suggested by an anonymous reviewer was that canonical views for haptics might be related to the main axis of elongation of an object. Axis of elongation was not explicitly controlled, but objects were always placed so that they were always either parallel or perpendicular to the trunk of the observer. In a post hoc analysis, we compared naming RTs from Block 1 for objects in parallel rather than in perpendicular orientations. Only data from the 32 objects that were presented in both parallel and perpendicular orientations were included; see the Appendix. The analysis excluded the 13 objects for which easy and hard orientations were both parallel or both perpendicular due to a $180^{\circ}$ easy-tohard orientation change. Objects presented in parallel orientations were named faster $(3,932 \mathrm{msec})$ than objects in perpendicular orientations $[4,880 \mathrm{msec} ; t(31)=-4.279$, $p<.001]$. Since most easy orientations were parallel to the trunk of the observer, the orientation of the main axis of elongation may, therefore, have caused the superior recognition of objects from easy orientations.

\section{Discussion}

First, these results replicated Klatzky et al.'s (1985) finding that 3-D haptic object recognition can be both fast and accurate. The present findings extend these results by showing that initial recognition is also influenced by orientation. Objects presented at easy, canonical orientations were named faster and more accurately than those presented at hard orientations. Second, there was significant priming of naming, with objects being named faster and more accurately the second time than the first time that they were presented. This priming was not merely due to general improvement at the haptic identification task since it was object specific. New objects presented in the second block were not named faster than objects presented in the first block, and they were named slower than primed objects in the second block. Third, this priming was invariant with respect to orientation: There was no cost to either RTs or accuracy associated with a change in orientation from study to test. This replicated Reales and Ballesteros's (1999) finding of strong unimodal haptic priming of naming and extended it to show that such priming may be orientation invariant.

The initial orientation effects are probably caused by some orientations being more informative than others, leading to faster identification. Easy haptic orientations may be similar to the canonical orientations documented in vision (Palmer et al., 1981), whereas hard haptic orientations may be analogous to what Biederman and Gerhardstein (1993) termed accidental views. Some features that are diagnostic of an object's identity are not readily available in these orientations. Visually, when a mug is oriented so that its handle is occluded, it may be harder to recognize than when its handle is visible. Similarly, at hard haptic orientations, it may take longer to extract sufficient information for recognition to occur, even though all surfaces of an object were readily accessible from the hard views used in Experiment 1. A post hoc analysis suggested that haptic orientations were more canonical when the main axis of elongation of an object was parallel rather than perpendicular to the trunk of the observer's body. However, this factor was not explicitly controlled for in Experiment 1, so further research is necessary to test this hypothesis.

The lack of a difference between same-orientation and different-orientation priming suggests that the representations used in the process of haptic object recognition may be orientation invariant; there is no cost of an orientation change because there is no representation of orientation, and no specific orientation can therefore be primed. Note that this possibility is compatible with our finding of canonical orientation effects on initial recognition. Initial orientation effects may be due to relatively early stages of haptic object processing, whereas orientation-specific priming across several minutes must be due to the activation of relatively long-term, stable, object-specific representations. The lack of orientation-specific priming effects is, however, contrary to the findings of Newell et al. (2001) and Forti and Humphreys (2005), who reported superior sequential matching performance on same-orientation in comparison with different-orientation trials. One reason for this discrepancy may have been that information about object orientation is not stored long term, so it was simply not available by the second block of naming in Experiment 1. There is some evidence that haptic memory of objects may decay rapidly, over several seconds (Kiphart, Hughes, Simmons, \& Cross, 1992). Experiment 2 examined this hypothesis. Participants classified each object at test as being in either the same or a different orientation as compared with that when it had been named at initial presentation.

\section{EXPERIMENT 2}

In Experiment 2, blindfolded, sighted participants named familiar objects in easy or hard orientations. In an unexpected test block, participants then decided whether each object was in the same orientation as it had been at study or in a different orientation. If the haptic system had 
not formed a stable, persistent orientation-dependent representation, then participants should not have been able to accurately accomplish this task.

\section{Method}

Participants. Ten right-handed students of the University of Liverpool participated in return for course credit. Eight were female. Ages ranged from 18 to 22 years ( $M=19$ years).

Stimuli. The same stimuli were used as in Experiment 1.

Design and Procedure. Experiment 2 replicated Experiment 1 , except for the following points. In Block 2, participants stated whether the object was presented at the same or at a different orientation than it had been in Block 1. No new items were introduced in Block 2 . Participants were informed that Block 2 would be a same-different orientation task during the break between Block 1 and Block 2; thus, they did not know during Block 1 that they would be required to remember the orientation in which the objects were presented.

\section{Results}

One participant was replaced because voice-key errors occurred on over $20 \%$ of trials. Naming in Block 1 was similar to naming in Block 1 of Experiment $1(4,053 \mathrm{msec}$, $8 \%$ errors). In Block 2, participants identified whether an orientation change had occurred from study to test quite accurately. Single-sample $t$ tests indicated that sameorientations were identified significantly above chance $[M=88 \%, S D=9 \%, \mu=50 \% ; t(9)=14.318, p<.001]$, as were different orientations $[M=87 \%, S D=10 \%, \mu=$ $50 \% ; t(9)=12.043, p<.001]$.

\section{Discussion}

The results of Experiment 2 show that the orientationinvariant priming observed in Experiment 1 was not attributable to a failure to encode the orientation in which the object had been presented at study. Participants quite accurately classified objects as being in either the same or a different orientation at test as compared with at study. Thus, although participants were not informed that they were required to remember the orientation of the objects presented for naming at study until they were due to begin the test block, they formed orientation-sensitive representations of the objects.

Another reason for the lack of orientation-specific priming in Experiment 1 was that this priming may have been largely conceptual or semantic rather than perceptual. Such nonperceptual priming would not be expected to be associated with strong effects of orientation. Experiment 3 was conducted to determine whether a significant proportion of the priming observed in Experiment 1 occurred at haptic stages of processing.

\section{EXPERIMENT 3}

Reales and Ballesteros (1999) argued that the dissociation between the implicit and explicit tasks in their experiments indicated that the haptic and visual priming they observed was presemantic. Additionally, they found no modality specificity in either implicit or explicit tasks. As was noted earlier, their argument assumes that the level of processing dissociates implicit and explicit memory and that implicit memory primarily reflects perceptual priming.
Lacey and Campbell (2006) argued that different representational codes - including a verbal code - could underpin cross-modal priming between vision and haptics. Thus, the priming of naming found by Reales and Ballesteros cannot be assumed to be purely presemantic.

The literature on haptic-specific priming has not been conclusive. Easton et al. (1997) found a marginally significant within-modality priming advantage in visual and haptic naming tasks, although there was no main effect of study modality on performance in either test modality. Bushnell and Baxt (1999) also found evidence for modality-specific representations, but used an old-new recognition task and thus provided no measure of priming. Furthermore, their study only assessed recognition by young children, who may display different recognition performance than adults.

We manipulated study modality in Experiment 3 to examine whether any of the priming observed in Experiment 1 was specific to the haptic modality. As in Experiment 1, participants named familiar objects. However, half of the objects were presented visually at study, and the other half were presented haptically. At test, all objects were then presented haptically at easy orientations. Visual presentations were photographs of different exemplars of the familiar objects that would be presented at test. Similar semantic and conceptual information should be activated after naming an object presented visually or haptically: For example, a kettle has the same name and function whether it is identified by touch or by vision. If the priming observed in Experiment 1 were due solely to semantic or name priming, or to the activation of bimodal perceptual representations accessible from either vision or haptics, then there should be no difference in performance at test attributable to study modality. However, if some component of the priming is specifically haptic, then haptic priming should be greater than visual priming.

\section{Method}

Participants. Thirty right-handed students, aged 18 to 40 years $(M=20)$, of the University of Liverpool participated in exchange for course credit. Twenty-five were female.

Stimuli. The haptic stimuli were the same as those used in Experiments 1 and 2; see the Appendix. The visual stimuli were 45 photographs of different exemplars of each of the haptic object categories. The photographs were sourced from the Internet, and they depicted the objects both in isolation and in canonical orientations. The photographs were resized to occupy an area of $300 \times 300$ pixels on the computer screen.

Design and Procedure. Objects were divided into three sets of 15 objects so that each set contained a similar variety of shapes and materials; see the Appendix. Participants were allocated to six groups of 5. The first block consisted of two sub-blocks, with one object set being shown visually in one sub-block and another object set being presented haptically in the other sub-block. All three sets of objects were then presented haptically in the second block. Each group shared the same sets of objects with one other group: One was given the visual set followed by the haptic set, and the other group was given the haptic set followed by the visual set. A Latin square design was used to counterbalance the allocation of object sets to groups.

The procedure for haptic trials was identical to that in Experiment 1 , with the exception that objects were always presented in easy orientations. Since visual recognition of objects is faster than haptic recognition, the visually presented objects were shown twice 
to approximately equate the study time to that of the haptically presented objects in Block 1. First, a photograph of each object was presented in the center of the Macintosh computer screen for $2 \mathrm{sec}$ for participants to name. Second, a photograph of each object was presented for $1 \mathrm{sec}$, and participants named one of the materials from which the object was made. This second presentation also encouraged participants to attend to at least one nonshape feature that would typically be perceived when haptically identifying an object. The Appendix lists accepted material names for each object.

Participants undertook 45 trials in Block 1: 15 haptic naming, 15 visual naming, and 15 visual naming of object materials. Participants then named 45 objects in Block 2: 15 haptically primed objects, 15 visually primed objects, and 15 unprimed objects. Participants were given a brief break between the two experimental blocks. On completion of the experimental trials, participants were read a list of the objects that had been presented during the experiment. Participants stated whether each object had been presented in Block 1 either visually or haptically, or whether each had been presented only in Block 2 .

\section{Results}

No participants were replaced in Experiment 3. Participants identified objects correctly on $96 \%$ of all trials, including those trials later excluded from the analysis due to voice-key errors. Trials were excluded from RT analyses if a voice-key error ( $4 \%$ of trials) or movement error $(<1 \%)$ was made, or if an incorrect response was given (4\%). Trials that presented an object for which an incorrect response was given in the other block were also excluded (7\%). Overall, $84 \%$ of trials were included in the RT analyses. Block 1 data was not included in the main analysis; the means of median naming RTs and the percentage of naming errors in Block 1 were $1,072 \mathrm{msec}$ and 1\% errors for visual study, and 4,293 msec and 5\% errors for haptic study.

A mixed ANOVA was conducted on the median correctnaming RTs and on the percentage of naming errors. Study modality (visual, haptic, or unstudied) was used as a within-participants factor. Group was used as a betweenparticipants factor in the by-participants analysis. Object set was used as a between-items factor in the by-items analysis. Effects involving these latter two counterbalancing factors are not reported. Because the data in the by-items analysis violated the assumption of sphericity, Huynh-Feldt correction was applied.

There was a significant main effect of study type for RTs $\left[F_{\mathrm{p}}(2,48)=124.737, p<.001\right.$, see Figure $3 ; F_{\mathrm{i}}(1.246$, $52.342)=27.064, p<.001]$, but not for errors $\left[F_{\mathrm{p}}(2,48)=\right.$ $\left.0.389, p=.68 ; F_{\mathrm{i}}(1.887,79.248)=0.387, p=.67\right]$. Haptically studied objects were named fastest $(3,149 \mathrm{msec})$, followed by visually studied objects $(3,508 \mathrm{msec})$. Unstudied objects were named slowest $(4,458 \mathrm{msec})$. Pairwise comparisons using Bonferroni correction revealed that haptically primed objects were recognized significantly faster $(359 \mathrm{msec})$ than visually primed objects, which in turn were recognized significantly faster $(977 \mathrm{msec})$ than unstudied objects. Thus, approximately a quarter of the priming was specific to objects studied haptically rather than visually in Block 1 .

The final part of Experiment 3 tested recall of original study modality. To account for response bias, $d^{\prime}$ scores were computed for each of the possible responses. Many participants scored $100 \%$ for at least one of the three re-

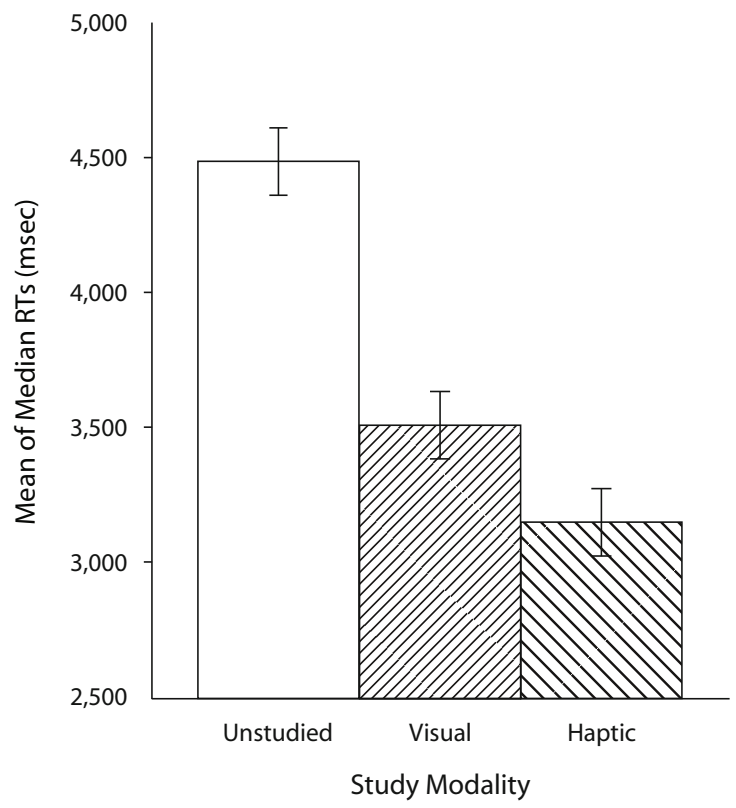

Figure 3. Means of median response times (RTs, by participants) by study modality when recognizing objects haptically at test in Experiment $3(N=30)$. Error bars show 95\% withinparticipants confidence intervals (Loftus \& Masson, 1994).

sponse options, so scores were combined across participants. Misses were trials on which an object was misclassified as belonging to another condition. For example, a trial on which a visually studied object was classified as being unstudied or haptically studied was a miss trial for visually studied objects. The same trials were also false alarms for other conditions; thus, a trial on which a visually studied object was classified as being haptically studied was a false-alarm trial for haptically studied objects. Participants were quite accurate at identifying the study modality of unstudied $\left(83 \%, d^{\prime}=2.56\right)$, visually studied $\left(84 \%, d^{\prime}=2.85\right)$, and haptically studied $\left(92 \%, d^{\prime}=2.58\right)$ objects during the final part of Experiment 3.

\section{Discussion}

Substantial within-modal and cross-modal priming of naming was observed in Experiment 3: Both haptically and visually studied objects were named faster than unstudied objects. Most importantly, haptically studied objects were named faster than visually studied objects. Thus, although a substantial component of the observed priming could be explained by semantic, verbal, or bimodal (visualhaptic) representations, a significant component - around 360 msec - could not. Unlike the complete cross-modal transfer observed between the visual and haptic modalities observed by Reales and Ballesteros (1999), here we found an advantage for objects studied haptically at both study and test. Note that this result is not necessarily contrary to their findings. The same 3-D exemplars were seen and felt from the same vantage point in the study conducted by Reales and Ballesteros (in press), whereas different ex- 
emplars of objects were shown from different orientations for visual and haptic presentation in Experiment 3. This introduced differences beyond the change in modality.

Although the difference we observed between haptic and visual priming might be attributable to several factors - the change of modality or exemplar, or the change from 2-D to 3-D - all of these factors alter the perceptual input while keeping the semantic information and verbal label the same. Therefore, the main reason why an advantage was found for haptic priming must be that a significant proportion of priming in Experiment 3-and in Experiment 1 -was mediated by long-term, object-specific perceptual representations.

Participants could quite accurately identify the study modality of each object, indicating that the source of the memory was stored. Even if some of the priming observed in this study was underpinned by bimodal representations derived from haptics and/or vision, these results demonstrate that information about input modality is available. Thus, either the bimodal representations are qualitatively different according to study modality - which seems unnecessary, given that they may be relatively abstract representations of shape-or additional, modality-specific episodic markers exist. Another possibility is that, rather than the existence of a specific marker indicating the source modality of a given input, the combination of several modality-specific features may indicate the source of the representation. For example, if the color of an object is remembered, then it must have been studied visually.

\section{EXPERIMENT 4}

We have established that the lack of orientation sensitivity found in Experiment 1 in a long-term name priming task was due neither to people failing to code object orientation (Experiment 2), nor to the priming being nonperceptual (Experiment 3). Experiment 4, therefore, returned to the question that we initially posed. Is the haptic recognition of familiar objects dependent on the orientation at which they are presented? We addressed this issue by presenting unfamiliar as well as familiar objects in a potentially more sensitive task - that of old-new recognition-while still testing for long-term orientation specificity (cf. Forti \& Humphreys, 2005; Lacey et al., 2007; Lawson, in press).

Orientation effects should be easier to detect in tasks that maximize the involvement of perceptual representations and reduce the influence of other factors, such as semantics, since nonperceptual representations are unlikely to exhibit orientation sensitivity. The results of Experiment 3 suggested that much of the priming observed in Experiment 1 may have been nonperceptual, so it may not have provided a sensitive test of orientation effects. To test this possibility, in Experiment 4, we presented unfamiliar as well as familiar objects. Unfamiliar objects lack semantic, conceptual representations, so orientation effects may be easier to detect using such stimuli.

An alternative reason for the lack of orientation-sensitive priming in Experiment 1 may have been that orientation- invariant, nonshape features - such as texture or temperature-drove the perceptual priming in that study. In this case, performance with unfamiliar objects with similar orientation-invariant features to familiar objects should also be orientation invariant. Such invariant features could not be used to identify objects in Newell et al.'s (2001), Lacey et al.'s (2007), and Lawson's (in press) experiments, since all of their stimuli were made from the same material. Forti and Humphreys (2005) only tested transfer from haptic study to visual object recognition, so orientationinvariant haptic features, such as temperature, were not useful at test. Therefore, in all four studies that have reported orientation effects on haptic object recognition, orientation dependence may have been due to the absence of informative orientation-invariant features, whereas orientation invariance in Experiment 1 may have been due to their presence. Since such features are normally available for everyday haptic object recognition, it is important that we establish whether orientation effects can be observed for objects possessing orientation-invariant features.

The long-term name priming task used in Experiment 1 also differed from previous studies that found orientation dependence in haptic object recognition. These studies measured performance on shorter term matching (Forti \& Humphreys, 2005; Lawson, in press) and in old-new recognition and identification tasks (Lacey et al., 2007; Newell et al., 2001). As was noted earlier, the reliability —and, therefore, the power and sensitivity_of implicit measures, such as priming of naming, has been questioned (Buchner \& Brandt, 2003; Buchner \& Wippich, 2000; Meier \& Perrig, 2000). It is therefore possible that the discrepancy between the results of Experiment 1 and earlier studies (Forti \& Humphreys, 2005; Lacey et al., 2007; Lawson, in press; Newell et al., 2001) was due to its use of a relatively insensitive measure.

The influence of object familiarity, the presence of nonshape orientation-invariant features, and the use of a potentially more reliable task than name priming were examined in Experiment 4. We used an old-new recognition task to assess orientation sensitivity for familiar and unfamiliar objects. Participants first studied half of the familiar and unfamiliar objects presented at either easy or hard orientations. They then classified all of the familiar and unfamiliar objects as being either previously studied (old) or new. Half of the old objects were presented in the same orientation at study and test, and the other half changed orientation from study to test.

\section{Method}

Participants. Thirty-two students of the University of Liverpool participated in exchange for course credit. Of these, 19 were female, and 2 were left-handed. Ages ranged from 18 to 35 years $(M=20)$.

Stimuli. The 32 familiar objects were a subset of those used in Experiments 1-3; see the Appendix. A set of 32 unfamiliar objects was then produced, each of which was approximately matched to a familiar object in shape, size, texture, and material; see Figure 4. The unfamiliar objects included unusual, difficult-to-name objects and common objects modified to be difficult to recognize. For example, one unfamiliar object was a computer hard drive with a section of its casing removed; another was an ice-cream scoop that was bent in two places to leave a hole in the middle of the scoop and that had 
an unusually shaped handle and an extra piece of plastic glued on A full set of photographs of the unfamiliar objects is available from the Psychonomic Society's Web archive (www.psychonomic.org/ archive). Each unfamiliar object was glued to a $20-\mathrm{cm}^{2}$ ceramic tile so that its main axis of elongation was oriented in the same way as its matched familiar object. The same easy and hard orientations were assigned to it as for its matched familiar object on the basis of this axis.

Design and Procedure. To establish that the unfamiliar objects were indeed unfamiliar, 5 participants who did not take part in Experiment 4 tried to identify them haptically. Forty unfamiliar objects were presented sequentially, along with five familiar objects that were included to ensure that people were trying to do the task. Only unfamiliar objects that were given no name or very different names by at least three of the participants were used in the main experiment. Objects were divided into eight sets, with four familiar and four unfamiliar objects in each set, and with a similar variety of shapes and materials in each set; see the Appendix.

Participants were allocated to eight groups. Each group was assigned four sets of objects to be the old items that were presented in both experimental blocks. Two of these sets were presented in easy orientations in the study block, and two were presented in hard orientations. Of each of these pairs of sets, one was presented in the same orientation at study and test, and the other set was presented in a different orientation at study and test. The other four sets of objects were presented only once as the new items in the test block. Two of these new sets were presented in easy orientations, and two were presented in hard orientations. The object sets assigned to each group were rotated using a Latin square design so that no two groups received the same combination of sets. Each object appeared in all possible combinations of orientation and orientation change an equal number of times.

Each trial was identical to the haptic trials in Experiment 1, except for the following points. Study trials were limited to $5 \mathrm{sec}$, after which a single high-pitched beep indicated that the participant should stop exploring the object. Participants were told to explore each object for the full $5 \mathrm{sec}$ and not to make any response. They were told that they would be asked to remember the objects later in the experiment. Study trials were presented in a random order.

In test trials, participants were allowed unlimited time to explore each object. They stated whether it was an "old" object—one that had previously been studied - or a "new" object—one that had not appeared in the study phase. Each trial ended when the participant responded. Objects were presented in the same order for all participants. Thus, the order of conditions in the test block was pseudorandomly mixed.

Participants were given a block of 32 study trials comprising eight familiar and eight unfamiliar objects in easy orientations, and eight familiar and eight unfamiliar objects in hard orientations. They then completed a block of 64 test trials, comprising 16 familiar and 16 unfamiliar new objects, 8 familiar and 8 unfamiliar old objects in the same orientation as that in the prime block (half at easy and half at hard orientations), and 8 familiar and 8 unfamiliar objects in a different orientation to that presented in the prime block (half at easy and half at hard orientation). Participants were given a brief break between the study and test blocks.
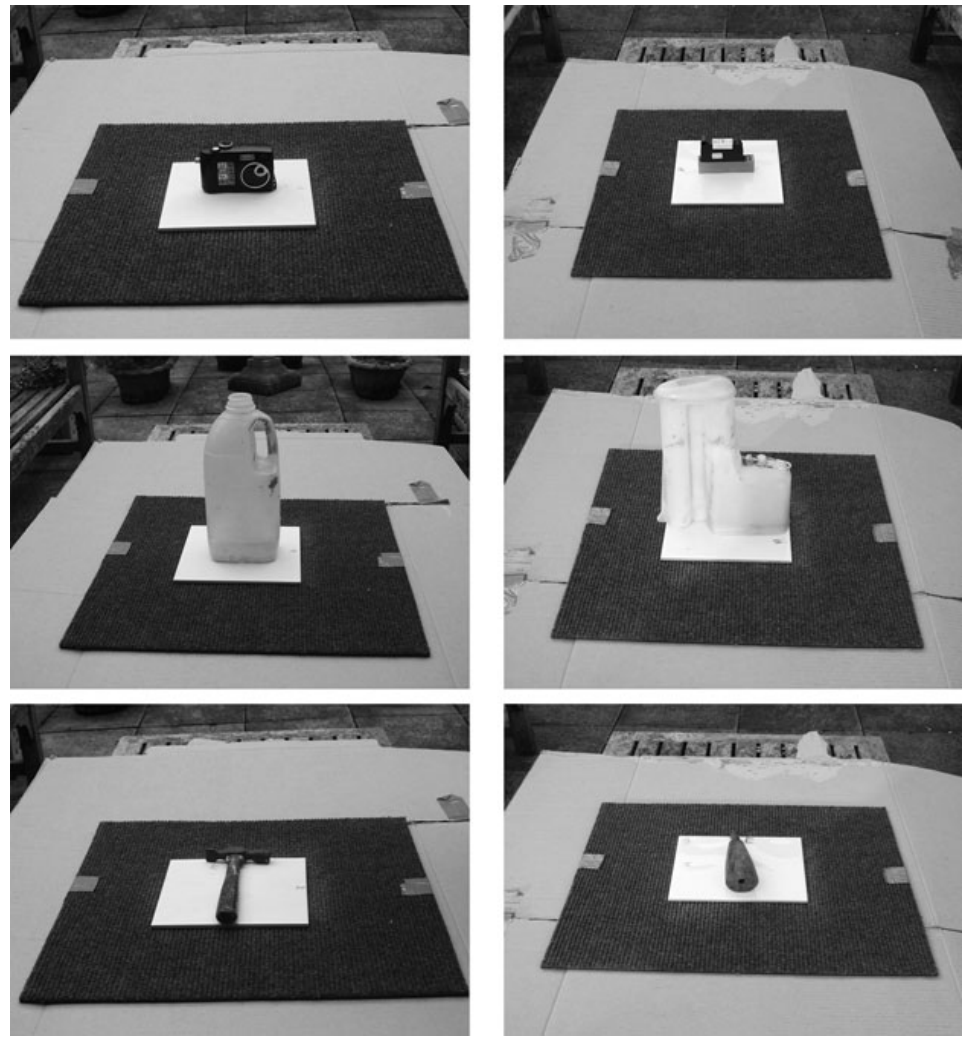

Figure 4. Photographs of matched pairs of familiar (left) and unfamiliar (right) objects both placed in easy orientations. Pictured from top to bottom are a camera and printer cartridge, a milk bottle and part of the plumbing of a toilet cistern, and a hammer and part of a chair leg sawn in half. 


\section{Results}

Four participants were replaced because voice-key errors occurred on over $20 \%$ of trials. Trials were excluded from RT analyses if a voice-key error ( $4 \%$ of trials) or movement error $(1 \%)$ was made, or if an incorrect response was given $(16 \%)$.

The effect of the initial orientation (easy or hard) on recognition memory was not tested in these ANOVAs, because each orientation was not presented enough times, and this issue was not the focus of interest in Experiment 4. However, the overall results were consistent with our finding of a benefit for canonical orientations in Experiment 1. At test, recognition memory for easy orientations was around 150-200 msec faster than that for hard orientations. Mean values for the easy and hard orientations were as follows: old-familiar objects, 3,065 msec and 3,229 msec, respectively; old-unfamiliar objects, $4,300 \mathrm{msec}$ and $4,472 \mathrm{msec}$; new-familiar objects, $3,950 \mathrm{msec}$ and 4,131 msec; newunfamiliar objects, 4,789 $\mathrm{msec}$ and 4,990 $\mathrm{msec}$. There were no overall effects on errors.

Mixed ANOVAs were conducted on RTs and percentage errors. In the by-participants analyses, familiarity (familiar or unfamiliar) and orientation (same or different) were within-participants factors, and group was a betweenparticipants factor. In the by-items analyses, orientation was a within-items factor, whereas familiarity and object set were between-items factors. Effects involving the counterbalancing factors of group and object set are not reported.

There was a significant main effect of familiarity for RTs $\left[F_{\mathrm{p}}(1,24)=47.126, p<.001 ; F_{\mathrm{i}}(1,48)=51.487, p<\right.$ $.001]$ and errors $\left[F_{\mathrm{p}}(1,24)=37.934, p<.001 ; F_{\mathrm{i}}(1,48)=\right.$ $27.758, p<.001]$. Old, familiar objects were recognized

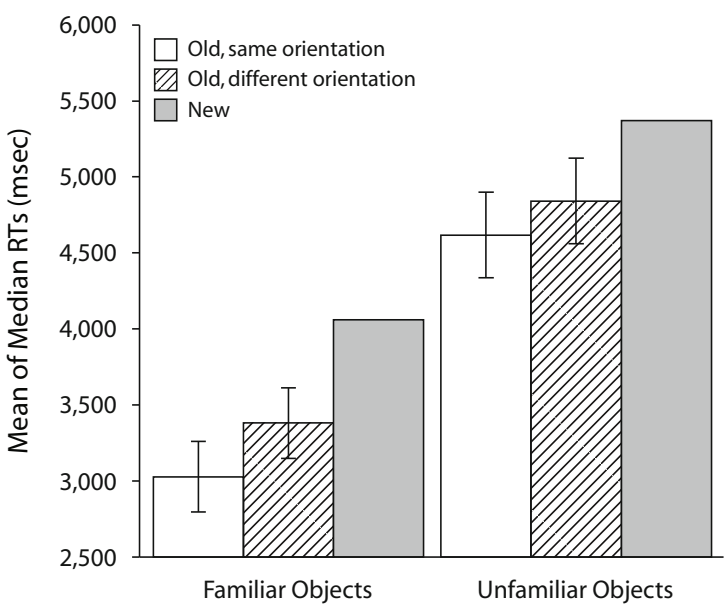

Figure 5. Means of median response times (RTs, by participants; $N=32$ ) for the recognition of familiar and unfamiliar objects separated by orientation at test (same or different). Error bars show $95 \%$ within-participants confidence intervals calculated using the error term of the familiarity $\times$ orientation interaction (Loftus \& Masson, 1994). Error bars are omitted for new objects, since they were not included in the main ANOVA.

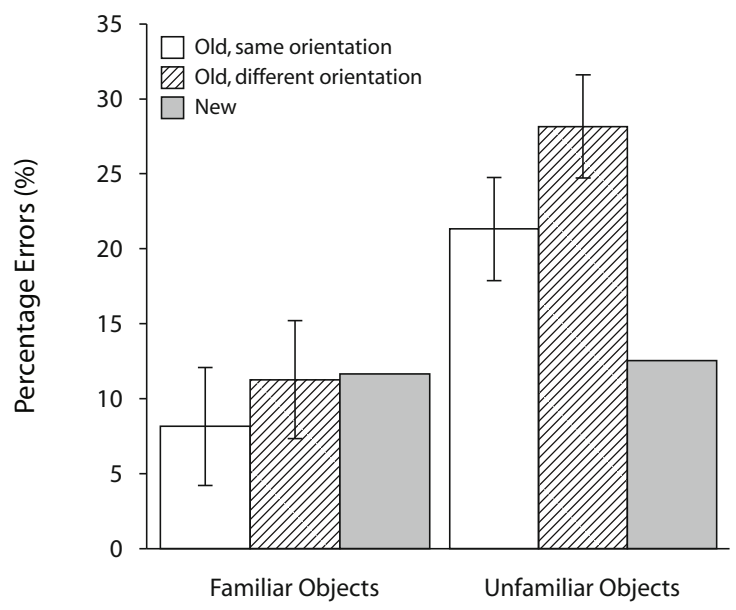

Figure 6. Mean percentage errors (by participants; $N=32$ ) of recognition of familiar and unfamiliar objects for new objects and for old objects separated by orientation at test (same or different). Error bars show $95 \%$ within-participants confidence intervals calculated using the error term of the familiarity $\times$ orientation interaction (Loftus \& Masson, 1994). Error bars are omitted for new objects, since they were not included in the main ANOVA.

faster $(3,209 \mathrm{msec})$ and more accurately ( $9 \%$ errors) than old, unfamiliar objects $(4,352 \mathrm{msec}, 29 \%)$.

There was a significant main effect of orientation for RTs by participants but not by items $\left[F_{\mathrm{p}}(1,24)=5.304, p=.03\right.$; $\left.F_{\mathrm{i}}(1,48)=0.357, p=.55\right]$, and for errors $\left[F_{\mathrm{p}}(1,24)=8.294\right.$, $\left.p=.008 ; F_{\mathrm{i}}(1,48)=4.569, p=.038\right]$. Objects placed in the same orientation in both blocks were recognized faster and more accurately $(3,646 \mathrm{msec}, 16 \%$ errors $)$ than objects placed in different orientations (3,916 msec, $22 \%$ ).

Importantly, there was no familiarity $\times$ orientation interaction for RTs $\left[F_{\mathrm{p}}(1,24)=0.385, p=.54\right.$, see Figure 5; $\left.F_{\mathrm{i}}(1,48)=3.026, p=.088\right]$ or errors $\left[F_{\mathrm{p}}(1,24)=1.034\right.$, $p=.32$, see Figure $\left.6 ; F_{\mathrm{i}}(1,48)=0.789, p=.38\right]$. Furthermore, the marginally significant effect for RTs in the byitems analysis reflected a trend for greater effects of orientation for the familiar than for the unfamiliar objects. There was no evidence that orientation specificity for old-new recognition was greater for unfamiliar objects, contrary to the predictions based on familiarity outlined earlier.

New objects were not included in the above analysis, since orientation was not a meaningful variable for objects only presented once. Means are reported here for completeness. The mean of median RTs and the mean percentage errors for new-familiar objects were 4,065 msec and $12 \%$, respectively, whereas for new-unfamiliar objects, they were $4,882 \mathrm{msec}$ and $14 \%$, respectively.

\section{Discussion}

First, both familiar and unfamiliar objects were recognized best when placed in the same orientation at study and test as opposed to when they were placed in different orientations. Second, although performance overall was both faster and more accurate for familiar objects than for unfa- 
miliar objects, there was no interaction between familiarity and orientation change. These results replicate similar findings for unfamiliar objects (Lacey et al., 2007; Newell et al., 2001) and for models of familiar objects (Lawson, in press) and extend them to a much broader range of familiar and unfamiliar 3-D objects possessing a variety of orientationinvariant cues, such as temperature and texture.

Experiment 4's results contrast with the orientationinvariant priming of naming found for familiar objects in Experiment 1. These results demonstrate that it was not merely object familiarity per se that resulted in a lack of orientation sensitivity in our first study. Another explanation for orientation invariance in Experiment 1 was that orientation-invariant cues, such as texture and temperature, drove priming. Previous reports of orientationsensitive haptic object processing have used stimuli lacking such informative cues (Lacey et al., 2007; Lawson, in press; Newell et al., 2001). These studies used objects that did not have the variety of shapes and materials that characterize everyday objects and which lacked at least some of the characteristics to which the haptic system is best attuned (Klatzky, Lederman, \& Reed, 1987; Lederman \& Klatzky, 1990). All of the familiar objects that appeared in Experiment 4 were used in Experiment 1, so the same features (e.g., texture) were present in both studies. The orientation-sensitive performance found in Experiment 4 shows that the presence of orientation-invariant cues cannot explain the lack of orientation effects found in Experiment 1 . Nevertheless, orientation-invariant cues may have reduced orientation effects in all of the present studies, as compared with objects lacking these features.

The failure to find orientation-sensitive effects in Experiment 1 may primarily have been due to the lower reliability and sensitivity of the name priming task in comparison with the old-new recognition task used in Experiment 4. Familiar object naming is quite fast and accurate - even for haptic presentation - so a ceiling effect may have masked any influence of orientation changes in Experiment 1. However, old-new recognition of familiar objects in Experiment 4 was also quite fast and accurate, but it was still orientation specific. A more likely cause of the difference between the two studies is that old-new recognition is a more powerful and sensitive measure of orientation effects than name priming (Buchner \& Brandt, 2003; Buchner \& Wippich, 2000; Meier \& Perrig, 2000). Furthermore, the results of Experiment 3 suggest that much of the priming in Experiment 1 may have been nonperceptual, which would have contributed to the reduced sensitivity of the naming task to orientation changes in Experiment 1.

In Experiment 4, recognition overall was faster and more accurate for the familiar objects. The time allowed for study $(5 \mathrm{sec})$ and the average RT at test $(4 \mathrm{sec})$ was sufficient to allow covert naming of familiar objects in Experiment 4. Therefore, some of the benefit for familiar objects may have been due to people using semantic and naming information. Although semantic descriptions of unfamiliar objects may still have been possible, they would typically have been less specific and therefore of limited value for recognition.

\section{GENERAL DISCUSSION}

In Experiment 1, orientation changes did not influence the priming of the haptic recognition of familiar objects. In Experiment 2, we demonstrated that the null finding in Experiment 1 was not due to people's failing to encode the orientation of haptically presented objects. In Experiment 3, we showed that a significant amount of the priming observed in Experiment 1 was specific to haptically studied objects, but that a substantial component of the priming was not modality specific and was probably nonperceptual. Finally, in Experiment 4, we showed that orientation changes worsen performance on an old-new recognition task for both familiar and unfamiliar objects, consistent with the results of recent studies demonstrating haptic orientation specificity (Forti \& Humphreys, 2005; Lacey et al., 2007; Lawson, in press; Newell et al., 2001).

Experiment 1 found clear evidence that some orientations of familiar objects were preferred haptically, resulting in faster and more accurate naming. Thus, familiar objects appear to have haptically canonical orientations analogous to visually canonical orientations (Humphrey \& Jolicœur, 1993; Lawson \& Humphreys, 1998; Palmer et al., 1981). However, the results of Experiment 1 do not indicate whether the preferred orientations in haptics are the same as those in vision. Newell et al.'s (2001) finding - that the haptic system prefers a back orientation with respect to the observer's head in comparison with the visual system's preference for a front orientationsuggests that haptic and visual canonical orientations may differ. However, this does not necessarily mean that the visual and haptic systems use different representations. These effects may simply reflect differing biomechanical constraints on acquiring visual versus haptic information rather than modality-specific differences in coding objectspecific representations from different orientations.

An object placed in its visual canonical orientation may not be at the optimum orientation for haptic recognition and vice versa, since each modality may use a different reference frame. Furthermore, the reference frame used by haptics may change over time (Zuidhoek, Kappers, van der Lubbe, \& Postma, 2003) and may be biased by the position of the head and eyes and the presence of noninformative vision (Zuidhoek, Visser, Bredero, \& Postma, 2004). Additionally, the haptic system initially weights local features more heavily than global shape (Lakatos \& Marks, 1999). Further research would be required to establish how canonical representations translate across modalities.

Priming of naming of familiar objects in Experiment 1 was not orientation sensitive. Caution must be taken when failing to reject the null hypothesis, particularly since, in Experiment 4, recognition of both familiar and unfamiliar objects was found to be orientation dependent. First, a null result may occur when a paradigm does not invoke the mechanisms that it is intended to test. Experiment 2 thus served as a manipulation check, showing that participants were encoding long-term orientation-dependent represen- 
tations. Second, a null result may occur when a paradigm lacks sufficient power to detect an effect. As was noted earlier, implicit measures, such as name priming, may be relatively unreliable (Buchner \& Wippich, 2000; Meier \& Perrig, 2000). Third, the results of Experiment 3 suggest that the priming of naming in Experiment 1 may have been predominantly driven by nonperceptual priming. However, old-new recognition memory was orientation sensitive in Experiment 4. Perceptual representations may have exerted a more substantial influence on recognition performance in Experiment 4 than on name priming in Experiment 1; thus, orientation sensitivity was easier to detect.

These experiments did not test the effect of orientation changes on cross-modal object recognition. In part, this is due to the difficulty of equating orientation across modalities. For example, an object can be presented visually at a single, fixed orientation, whereas a haptically presented object is typically explored over several seconds using movements across several sides of an object. That orientation dependence may still arise under such circumstances (Forti \& Humphreys, 2005; Newell et al., 2001) is somewhat surprising.

The similarities between orientation sensitivity for haptic and visual object recognition provide preliminary evidence that the two modalities may use similar strategies to attain object constancy. Visual and haptic object recognition may involve independent processing routes, but may also converge on a single recognition system and use the same processes to analyze some properties - in this case, 3-D shape. Thus, with some modification, both the image-mediation and the directapprehension models of haptic object recognition may hold true (Lederman \& Klatzky, 1987). Image-mediation may represent one end of a continuum where the haptic system is forced to use predominantly visual mechanisms, particularly for unusual stimuli, such as 2-D raised-line pictures (Lederman et al., 1990). Direct-apprehension may represent the other extreme, at which purely haptic mechanisms are used. Everyday haptic object recognition may use both mechanisms. To examine the generality of this account, it is important that we examine how the haptic system attains object constancy across other transformations. For example, the visual system has consistently demonstrated size constancy in object recognition (see, e.g., Biederman \& Cooper, 1992; Furmanski \& Engel, 2000). If the haptic system processes size in the same way as the visual system, then it too may demonstrate size invariance in object recognition. To date, only Srinivas, Greene, and Easton (1997) have addressed this question. They provided evidence that the haptic system does not process size in the same way as it does vision for 2-D patterns. However, this proposition has not been tested with real, 3-D objects, for which the haptic system is better suited (Klatzky et al., 1987).

\section{AUTHOR NOTE}

This research was supported by an Engineering and Physical Sciences Research Council DTA studentship to the first author and by a fellowship from the Economic and Social Research Council (RES-000-27-0162) to the second author. Address correspondence to M. Craddock, School of
Psychology, University of Liverpool, Eleanor Rathbone Building, Bedford St. South, Liverpool L69 7ZA, England (e-mail: m.craddock@liv.ac.uk).

Note-Accepted by the editorial board of Editor-Elect Jeremy M. Wolfe.

\section{REFERENCES}

Amedi, A., Jacobson, G., Hendler, T., Malach, R., \& Zohary, E. (2002). Convergence of visual and tactile shape processing in the human lateral occipital complex. Cerebral Cortex, 12, 1202-1212.

Amedi, A., Malach, R., Hendler, T., Peled, S., \& Zohary, E. (2001). Visuo-haptic object-related activation in the ventral visual pathway. Nature Neuroscience, 4, 324-330.

Ballesteros, S., Reales, J. M., \& Manga, D. (1999). Implicit and explicit memory for familiar and novel objects presented to touch. Psicothema, 11, 785-800.

BIEDERMAN, I. (1987). Recognition-by-components: A theory of human image understanding. Psychological Review, 94, 115-147.

Biederman, I., \& COOPER, E. E. (1992). Size invariance in visual object priming. Journal of Experimental Psychology: Human Perception \& Performance, 18, 121-133.

Biederman, I., \& Gerhardstein, P. C. (1993). Recognizing depthrotated objects: Evidence for 3-D viewpoint invariance. Journal of Experimental Psychology: Human Perception \& Performance, 19, 1162-1183.

Buchner, A., \& BRANDT, M. (2003). Further evidence for systematic reliability differences between explicit and implicit memory tests. Quarterly Journal of Experimental Psychology, 56A, 192-209.

BUCHNER, A., \& WIPPICH, W. (2000). On the reliability of implicit and explicit memory measures. Cognitive Psychology, 40, 227-259.

Bushnell, E. W., \& BaXt, C. (1999). Children's haptic and crossmodal recognition with familiar and unfamiliar objects. Journal of Experimental Psychology: Human Perception \& Performance, 25, 1867-1881.

Cohen, J. D., MacWhinney, B., Flatt, M., \& Provost, J. (1993). PsyScope: An interactive graphic system for designing and controlling experiments in the psychology laboratory using Macintosh computers. Behavior Research Methods, Instruments, \& Computers, 25, 257-271.

Easton, R. D., Greene, A. J., \& SRInivas, K. (1997). Transfer between vision and haptics: Memory for 2-D patterns and 3-D objects. Psychonomic Bulletin \& Review, 4, 403-410.

Forti, S., \& Humphreys, G. W. (2005). Cross-modal visuo-tactile matching in a patient with a semantic disorder. Neuropsychologia, 43, 1568-1579.

Furmanski, C. S., \& Engel, S. A. (2000). Perceptual learning in object recognition: Object specificity and size invariance. Vision Research, 40, 473-484.

Grill-Spector, K., Kourtzi, Z., \& Kanwisher, N. (2001). The lateral occipital complex and its role in object recognition. Vision Research, 41, 1409-1422.

HAYWARD, W. (2003). After the viewpoint debate: Where next in object recognition? Trends in Cognitive Sciences, 7, 425-427.

HuMPHREY, G. K., \& JOLICCEUR, P. (1993). An examination of axis foreshortening, monocular depth cues, and visual field on object identification. Quarterly Journal of Experimental Psychology, 46A, 137-159.

Kiphart, M. J., Hughes, J. L., Simmons, J. P., \& Cross, H. A. (1992). Short-term haptic memory for complex objects. Bulletin of the Psychonomic Society, 30, 212-214.

Klatzky, R. L., Lederman, S. J., \& Metzger, V. (1985). Identifying objects by touch: An "expert system." Perception \& Psychophysics, 37, 299-302.

Klatzky, R. L., Lederman, S. J., \& Reed, C. (1987). There's more to touch than meets the eye: The salience of object attributes for haptics with and without vision. Journal of Experimental Psychology: General, 116, 356-359.

Klatzky, R. L., Loomis, J. M., Lederman, S. J., Wake, H., \& FuJITA, N. (1993). Haptic identification of objects and their depictions. Perception \& Psychophysics, 54, 170-178. 
Kourtzi, Z., Erb, M., Grodd, W., \& Bülthoff, H. (2003). Representation of the perceived 3-D object shape in the human lateral occipital cortex. Cerebral Cortex, 13, 911-920.

LACEY, S., \& CAMPBEll, C. (2006). Mental representation in visual/ haptic crossmodal memory: Evidence from interference effects. Quarterly Journal of Experimental Psychology, 59, 361-376.

LACEy, S., Peters, A., \& SAthian, K. (2007). Cross-modal object recognition is viewpoint-independent. PLOS ONE, 2, e890.

LAKATOS, S., \& MARKS, L. E. (1999). Haptic form perception: Relative salience of local and global features. Perception \& Psychophysics, 61, 895-908.

LAWSON, R. (1999). Achieving visual object constancy across plane rotation and depth rotation. Acta Psychologica, 102, 221-245.

LAWSON, R. (in press). A comparison of the effects of depth rotation on visual and haptic 3-D object recognition. Journal of Experimental Psychology: Human Perception \& Performance.

LAWson, R., \& Humphreys, G. W. (1996). View-specificity in object processing: Evidence from picture matching. Journal of Experimental Psychology: Human Perception \& Performance, 22, 395-416.

LAwson, R., \& Humphreys, G. W. (1998). View-specific effects of depth rotation and foreshortening on the initial recognition and priming of familiar objects. Perception \& Psychophysics, 60, 1052-1066.

LAWSON, R., \& Humphreys, G. W. (1999). The effects of view in depth on the identification of line drawings and silhouettes of familiar objects: Normality and pathology. Visual Cognition, 6, 165-195

Lederman, S. J., \& KlatZKY, R. L. (1987). Hand movements: A window into haptic object recognition. Cognitive Psychology, 19, 342368 .

Lederman, S. J., \& KLATZKy, R. L. (1990). Haptic classification of common objects: Knowledge-driven exploration. Cognitive Psychology, 22, 421-459.

Lederman, S. J., Klatzky, R. L., Chataway, C., \& Summers, C. D. (1990). Visual mediation and the haptic recognition of two-dimensional pictures of common objects. Perception \& Psychophysics, 47, 54-64.

Loftus, G. R., \& Masson, M. E. J. (1994). Using confidence intervals in within-subject designs. Psychonomic Bulletin \& Review, 1, 476-490.

Loomis, J. M., Klatzky, R. L., \& Lederman, S. J. (1991). Similarity of tactual and visual picture recognition with limited field of view. Perception, 20, 167-177.

MeIer, B., \& Perrig, W. J. (2000). Low reliability of perceptual priming: Consequences for the interpretation of functional dissociations between explicit and implicit memory. Quarterly Journal of Experimental Psychology, 53A, 211-233.

Newell, F., ERnst, M. O., Tuan, B. S., \& Bülthoff, H. (2001). Viewpoint dependence in visual and haptic object recognition. Psychological Science, 12, 37-42.

Palmer, S. E., Rosch, E., \& Chase, P. (1981). Canonical perspective and the perception of objects. In J. [B.] Long \& A. [D.] Baddeley (Eds.), Attention and performance IX (pp. 135-151). Hillsdale, NJ: Erlbaum.

ReAles, J. M., \& BALlesteros, S. (1999). Implicit and explicit memory for visual and haptic objects: Cross-modal priming depends on struc- tural descriptions. Journal of Experimental Psychology: Learning, Memory, \& Cognition, 25, 644-663.

Reed, C. L., Shoham, S., \& Halgren, E. (2004). Neural substrates of tactile object recognition: An fMRI study. Human Brain Mapping, 21, 236-246.

Srinivas, K., Greene, A. J., \& Easton, R. D. (1997). Visual and tactile memory for 2-D patterns: Effects of changes in size and left-right orientation. Psychonomic Bulletin \& Review, 4, 535-540.

Stankiewicz, B. J., Hummel, J. E., \& Cooper, E. E. (1998). The role of attention in priming for left-right reflections of object images: Evidence for a dual representation of object shape. Journal of Experimental Psychology: Human Perception \& Performance, 24, 732-744.

TARR, M. J., \& ChEng, Y. D. (2003). Learning to see faces and objects. Trends in Cognitive Sciences, 7, 23-30.

Thoma, V., \& Davidoff, J. (2006). Priming of depth-rotated objects depends on attention and part changes. Experimental Psychology, 53, 31-47.

Vuilleumier, P., Henson, R., Driver, J., \& Dolan, R. J. (2002). Multiple levels of visual object constancy revealed by event-related fMRI of repetition priming. Nature Neuroscience, 5, 491-499.

Zhang, M., Weisser, V. D., Stilla, R., Prather, S. C., \& Sathian, K. (2004). Multisensory cortical processing of object shape and its relation to mental imagery. Cognitive, Affective, \& Behavioral Neuroscience, 4, 251-259.

Zuidhoek, S., Kappers, A. M. L., van der Lubbe, R. H. J., \& Postma, A. (2003). Delay improves performance on a haptic spatial matching task. Experimental Brain Research, 149, 320-330.

Zuidhoek, S., Visser, A., Bredero, M. E., \& Postma, A. (2004). Multisensory integration mechanisms in haptic space perception. Experimental Brain Research, 157, 265-268.

\section{NOTE}

1. Analyses were also conducted using several different transformations to normalize RTs, including logarithmic and inverse transformations. None of these methods yielded results different from those reported here.

\section{ARCHIVED MATERIALS}

The following materials associated with this article may be accessed through the Psychonomic Society's Archive of Norms, Stimuli, and Data, www.psychonomic.org/archive.

To access these files, search the archive for this article using the journal name (Perception \& Psychophysics), the first author's name (Craddock), and the publication year (2008).

FILE: Craddock-P\&P-2008.zip

DESCRIPTION: The compressed archive file contains a total of 64 black and white photographs in .jpg format of the 32 novel exemplars used in Experiment 4 . Filenames indicate the familiar object to which these objects were matched and the orientation in which these objects were placed.

AUTHOR's E-MAIL ADDRESS: m.craddock@liv.ac.uk. 
Appendix

Object Names for the Familiar Items Used in Experiments 1-4, Alternative Names Accepted in Experiments 1-3, Material Names Accepted in Experiment 3,

Degree of Orientation Change in Experiments 1, 2, and 4, and Counterbalancing Sets for Experiments 1-4

\begin{tabular}{|c|c|c|c|c|c|c|}
\hline $\begin{array}{l}\text { Object } \\
\text { Names }\end{array}$ & $\begin{array}{c}\text { Accepted } \\
\text { Alternative } \\
\text { Names }\end{array}$ & $\begin{array}{c}\text { Accepted } \\
\text { Material } \\
\text { Names }\end{array}$ & $\begin{array}{c}\text { Orientation } \\
\text { Change }\end{array}$ & $\begin{array}{c}\mathrm{E} 1 / 2 \\
\text { Set }\end{array}$ & $\begin{array}{l}\text { E3 } \\
\text { Set }\end{array}$ & $\begin{array}{l}\text { E4 } \\
\text { Set }\end{array}$ \\
\hline Alarm clock & & Metal, glass & 90 & A & $\mathrm{A}$ & $\mathrm{B}$ \\
\hline Bottle & Milk bottle/carton & Plastic & 90 & $\mathrm{E}$ & $\mathrm{C}$ & $\mathrm{F}$ \\
\hline Bulldog clip & Clip & Metal & 90 & $\mathrm{D}$ & $\mathrm{C}$ & $\mathrm{H}$ \\
\hline Calculator & & Plastic, glass & 90 & B & B & B \\
\hline Camera & & Plastic, glass & 90 & A & A & A \\
\hline Cassette & Tape & Plastic & 90 & $\mathrm{E}$ & $\mathrm{C}$ & $\mathrm{C}$ \\
\hline Comb & & Plastic & 90 & $\mathrm{C}$ & B & N/A \\
\hline Fork & & Metal & 90 & A & A & N/A \\
\hline Hammer & & Wood, metal & 90 & A & A & $\mathrm{A}$ \\
\hline Holepunch & & Plastic, metal & 90 & $\mathrm{~B}$ & A & N/A \\
\hline Kettle & & Plastic & 90 & $\mathrm{E}$ & $\mathrm{C}$ & N/A \\
\hline Key & & Metal & 90 & $\mathrm{~B}$ & A & B \\
\hline Knife & & Metal & 90 & $\mathrm{D}$ & $\mathrm{C}$ & N/A \\
\hline Ladle & & Metal & 90 & $\mathrm{C}$ & B & $\mathrm{D}$ \\
\hline Measuring jug & Plastic jug, jug & Plastic & 90 & A & A & $\mathrm{H}$ \\
\hline Mouse & & Plastic & 90 & A & A & $\mathrm{H}$ \\
\hline Mug & Cup & Pot, ceramic & 90 & $\mathrm{D}$ & $\mathrm{C}$ & N/A \\
\hline Nail & & Metal & 90 & $\mathrm{C}$ & B & $\mathrm{E}$ \\
\hline Padlock & Lock, bike lock & Metal & 90 & $\mathrm{C}$ & B & G \\
\hline Paintbrush & Pastry brush & Wood, fibers & 90 & $\mathrm{C}$ & B & $\mathrm{N} / \mathrm{A}$ \\
\hline Pen & & Plastic, metal & 90 & B & A & $\mathrm{C}$ \\
\hline Pencil & & Wood & 90 & $\mathrm{E}$ & $\mathrm{C}$ & $\mathrm{F}$ \\
\hline Screwdriver & & Plastic, metal & 90 & $\mathrm{D}$ & B & $\mathrm{E}$ \\
\hline Shoe & & Leather & 90 & $\mathrm{D}$ & B & $\mathrm{N} / \mathrm{A}$ \\
\hline Spanner & Wrench & Metal & 90 & $\mathrm{C}$ & B & $\mathrm{C}$ \\
\hline Spoon & & Metal & 90 & $\mathrm{~B}$ & A & $\mathrm{N} / \mathrm{A}$ \\
\hline Stapler & & Metal & 90 & $\mathrm{C}$ & B & $\mathrm{D}$ \\
\hline Tap & & Metal & 90 & $\mathrm{~A}$ & $\mathrm{~A}$ & $\mathrm{E}$ \\
\hline Toothbrush & & Plastic, fibers & 90 & $\mathrm{E}$ & $\mathrm{C}$ & $\mathrm{N} / \mathrm{A}$ \\
\hline Tweezers & & Metal & 90 & $\mathrm{E}$ & $\mathrm{C}$ & $\mathrm{D}$ \\
\hline Whisk & Mixer & Metal & 90 & A & A & $\mathrm{N} / \mathrm{A}$ \\
\hline Whistle & & Metal & 90 & $\mathrm{C}$ & $\mathrm{B}$ & $\mathrm{G}$ \\
\hline Cigarette lighter & & Plastic, metal & 180 & $\mathrm{E}$ & $\mathrm{C}$ & $\mathrm{E}$ \\
\hline Corkscrew & Bottle opener & Wood, metal & 180 & $\mathrm{~B}$ & B & $\mathrm{B}$ \\
\hline Dustpan & & Plastic & 180 & B & A & $\mathrm{N} / \mathrm{A}$ \\
\hline Funnel & & Plastic & 180 & $\mathrm{D}$ & $\mathrm{C}$ & $\mathrm{D}$ \\
\hline Glasses & Sunglasses & Plastic, glass & 180 & $\mathrm{D}$ & B & $\mathrm{H}$ \\
\hline Peg & & Plastic, metal & 180 & $\mathrm{D}$ & $\mathrm{C}$ & $\mathrm{N} / \mathrm{A}$ \\
\hline Plug & & Plastic, metal & 180 & B & A & $\mathrm{F}$ \\
\hline Razor & & Plastic & 180 & A & A & A \\
\hline Remote control & TV clicker & Plastic & 180 & $\mathrm{C}$ & $\mathrm{B}$ & $\mathrm{G}$ \\
\hline Scissors & & Metal & 180 & $\mathrm{D}$ & $\mathrm{C}$ & $\mathrm{G}$ \\
\hline Sieve & & Plastic & 180 & $\mathrm{E}$ & $\mathrm{C}$ & $\mathrm{F}$ \\
\hline Tin opener & Can opener & Plastic, metal & 180 & $\mathrm{E}$ & $\mathrm{C}$ & $\mathrm{A}$ \\
\hline Torch & & Plastic, glass & 180 & B & B & $\mathrm{C}$ \\
\hline
\end{tabular}

(Manuscript received September 18, 2007; revision accepted for publication April 11, 2008.) 